\title{
Life Expectancy and its Socioeconomic Determinants in Iran
}

\author{
Somayeh Delavari ${ }^{1}$, Hamed Zandian² ${ }^{2}$ Satar Rezaei ${ }^{3}$, Mehdi Moradinazar ${ }^{4}$, Sajad Delavari ${ }^{5}$, Ali Saber ${ }^{6}$, Razieh \\ Fallah ${ }^{7}$
}

${ }^{1}$ Department of Medical Education, School of Medicine and Center for Educational Research in Medical Sciences (CERMS), Iran University of Medical Sciences, Tehran, Iran

${ }^{2}$ Department of Public Health, School of Health, Ardabil University of Medical Sciences, Ardabil, Iran

${ }^{3}$ Research Center for Environmental Determinants of Health, Kermanshah University of Medical Sciences, Kermanshah, Iran

${ }^{4}$ Research Center for Environmental Determinants of Health, Kermanshah University of Medical Sciences, Kermanshah, Iran

${ }^{5} \mathrm{PhD}$ Student of Health Policy, Health Human Resources Research Center, School of Management \& Information Sciences, Shiraz University of Medical Sciences, Shiraz, Iran

${ }^{6} \mathrm{Ph} . \mathrm{D}$. Candidate in Medical Ethics, Medical Ethics and History of Medicine Research Center, Tehran University of Medical Sciences, Tehran, Iran

${ }^{7}$ Ph.D. Student of Health Policy, Amol Imam Reza Hospital, Mazandaran University of Medical Sciences, Sari, Iran

\section{Type of article: Original}

\begin{abstract}
Introduction: Life expectancy at birth (LEB) is closely associated with the degree of economic and social development in developed and developing countries. This study aimed to examine the socioeconomic factors affecting LEB in Iran from 1985 to 2013.

Methods: Time series analysis was used to examine the effects of key explanatory factors (GDP per capita, number of doctors per 10,000 population, degree of urbanization, food availability, $\mathrm{CO} 2$ emission, total fertility rate, inflation rate, and literacy rate) on LEB in Iran from 1985 to 2013. Study data were retrieved from the Central Bank of Iran (CBI), Iranian Statistical Center (ISC), and World Bank. Augmented Dickey Fuller (ADF) and Banergy, Dolado, and Master (BDM) tests, Engle Granger approach, and an ordinary least-square (OLS) model were used to achieve the aim of the study. Data analysis was performed by Stata V.12 software.

Results: Our findings indicated that GDP per capita $(\mathrm{p}=0.003)$, number of doctors per 10,000 population $(\mathrm{p}=0.036)$, literacy rate $(\mathrm{p}=0.0001)$, and food availability $(\mathrm{p}=0.0001)$ have a positive and significant statistically effect on LEB. The relationship between total fertility rate and LEB was negative and significant $(\mathrm{p}=0.023)$. In addition, the effect of degree urbanization $(\mathrm{p}=0.811), \mathrm{CO} 2$ emission $(\mathrm{p}=0.185)$, and inflation rate $(\mathrm{p}=0.579)$ on LEB were not significant.

Conclusion: GDP per capita, number of doctors per 10,000 population, food availability, literacy rate, and total fertility were identified as the main factors affecting life expectancy in Iran. The study, however, suggests that life expectancy in Iran could be improved if attention is given to factors that reside outside of the health sector.
\end{abstract}

Keywords: Life expectancy, Time series, Socio-economic factors, Iran

\section{Introduction}

Life expectancy at birth (LEB) is defined as the average number of years one would be expected to live at birth. Life expectancy is commonly used as one of the main indicators to assess health status of a population in developed as well as developing countries, and it is also closely associated with the degree of economic and social development of a country or a region (1-3). Although life expectancy has increased at the global level in the last decades and increased

\section{Corresponding author:}

Razieh Fallah, Mazandaran University of Medical Sciences, Sari, Iran.

Tel.: +98.9183029489, Email: fallahrazieh@gmail.com

Received: May 12, 2016, Accepted: July 16, 2016, Published: October 2016

iThenticate screening: July 16, 2016, English editing: September 02, 2016, Quality control: September 26, 2016

(C) 2016 The Authors. This is an open access article under the terms of the Creative Commons Attribution-NonCommercialNoDerivs License, which permits use and distribution in any medium, provided the original work is properly cited, the use is noncommercial and no modifications or adaptations are made. 
quantity varies among countries, there is a high disparity between developed and developing countries. For example, based on a recent human development report, published in 2013, the gap between life expectancy in Japan is the highest in the world (86.6 years) and Sierra Leone has the lowest in the world (48.1 years) at 35.5 years. Or the disparity between developed and developed countries is about 11 years $(4,5)$. The differences between countries can be explained by long-term changes in social, cultural, economic, environmental, and health system factors. Health policymakers, in developed and developing countries, are concerned about this discrepancy among countries, and they are interested to know the main factors that affect life expectancy. Previous studies highlighted the effect of different variables such as gross domestic production (GDP) per capita, healthcare expenditure, urbanization rate, $\mathrm{CO} 2$ emission, doctors or beds per 10,000 population, literacy rate, total fertility rate, misery index (unemployment + inflation rate), food production index, pharmaceutical, income inequality, and exchange rate on life expectancy (2-8). Bayatti et al. (6) reported the main determinant of life expectancy at birth in EMR (Eastern Mediterranean Region), based on the Grossman model, between 1995 and 2007 using a panel data of 21 countries. Their results demonstrated that income per capita, years schooling, food availability, level of urbanization and employment ratio were the main factors affecting LEB. Sede and Ohemeng3 also demonstrated per capita income, years schooling, and government expenditures on health were the main socioeconomic factors affecting life expectancy in Nigeria (1980-2011). Gulis (9) has examined the main determinants of life expectancy of 156 developed and developing countries. His study demonstrated that income per capita, public health spending, safe drinking water, calorie intake, and literacy were the main determinants of life expectancy. An analysis of three decades showed that the average of life expectancy at birth in Iran between 1980 and 1990 was 57.2 years; $1991-2000$ was 67.8 years; 2001-2011 was 71.6 years. In other words, the LEB in Iran has increased from 55 years in 1980 to 73 years in 2011 (10). Understanding the main factors affecting increased LEB in Iran over the three past decades could provide important insights and further evidence for health policymakers to support governmental health efforts for promotion of health status. However, this study attempted to examine the impact on some of the main socioeconomic factors on life expectancy at birth in Iran from 1985 to 2013. We hope the results of this study could help policymakers to gain an appropriate view about the determinants of life expectancy in the country.

\section{Material and Methods}

\subsection{Data Sources}

The study setting was Iran, which consists of 31 provinces, based on the census 2011, with a population of around $75,149,669$ of people and is located in the Eastern Mediterranean Region with an area of 1,648,000 $\mathrm{km}^{2}$. The data on number of doctors per 10,000 population (DOC), inflation rate (INF), and literate rate (LIT) were retrieved from the Iranian Statistical of Center (ISC) and Central Bank of Iran (CBI). Also, information on life expectancy at birth, food production index (FPI), urbanization degree (URB), gross domestic production (GDP), total fertility rate (TFR), and $\mathrm{Co}_{2}$ emission was obtained from the World Bank. These explanatory variables were chosen based on literature review and their availability $(2-5,7,8)$. The study covers the period 1985-2013 (28 years), which has a sufficient degree of freedom to capture a considerably large proportion of the effect of socioeconomic variables on life expectancy in Iran over time.

\subsection{Statistical Analysis}

In the current study, the following primary model was used: LEB = f (FPI, URB, GDP, DOC, INF, $\mathrm{CO}_{2}$, TFR, LIT). Based on this model, the following econometric model was used in order to determine the key explanatory factors affecting life expectancy at birth in Iran: LLEB $_{t}=a_{0}+\beta_{1}$ LFPI $_{t}+\beta_{2}$ LURB $_{t}+\beta_{3}$ LGDP $_{t}+\beta_{4}$ LDOC $_{t}+\beta_{5} \operatorname{LINF}_{t}+$ $\beta_{6} \mathrm{LCo}_{\mathrm{t}}+\beta_{7} \mathrm{LTFR}_{\mathrm{t}}+\beta_{8} \mathrm{LLIT}_{\mathrm{t}}+\mathrm{u}_{\mathrm{t}}$, where $\alpha_{0}=$ intercept, $\beta_{1}=$ coefficient of logarithm FPI, $\beta_{2}=$ coefficient of logarithm URB, $\beta_{3}=$ coefficient of logarithm GDP, $\beta_{4}=$ coefficient of logarithm DOC, $\beta_{5}=$ coefficient of logarithm IFR, $\beta_{6}=$ coefficient of logarithm $\mathrm{CO}_{2}, \beta_{7}=$ coefficient of logarithm TFR, $\beta_{8}=$ coefficient of logarithm LIT, $\mu=$ error term. In a time series data, it is an important to determine whether or not the variables are stationary and cointegration (11). Augmented Dickey Fuller (ADF) and Banergy, Dolado, and Master (BDM) tests were used to examine the stationary and cointegration of the variables included in the study (12). An Engle Granger approach was used in order to determine whether there is a long-run relationship between life expectancy and its determinants (13). Based on econometrics text, if there is a long-run relationship between dependent variable and its determinants, an ordinary least-square (OLS) model produces consistent parameter estimates $(14,15)$. In addition, variance inflation factor (VIF) and tolerance tests for assessing the collinearity and Shapiro-Wilk W test were used to assess the normality distribution of residuals of the explanatory variables $(16,17)$. A $P$-value less than 0.05 was considered to be statistically significant, and all the analyses were performed by the Stata v.12 software. 


\section{Results}

The descriptive statistics of variables included in the study are presented in Table 1. As can be seen in Table 1, the mean of LEB was 67.9 years with SD of 5.08 years (ranged from 56 and 74 years) during the studied period. Mean of GDP per capita also rose from 3590 in 1985 to 4763 in 2013. In addition, the number of doctors per 10,000 population increased from 3.6 at the beginning of the study to 14.3 at the end. The LEB in Iran increased from 56 years in 1985 to 74 years in 2013 ( +20 years); the trend of LEB is shown in Figure 1.

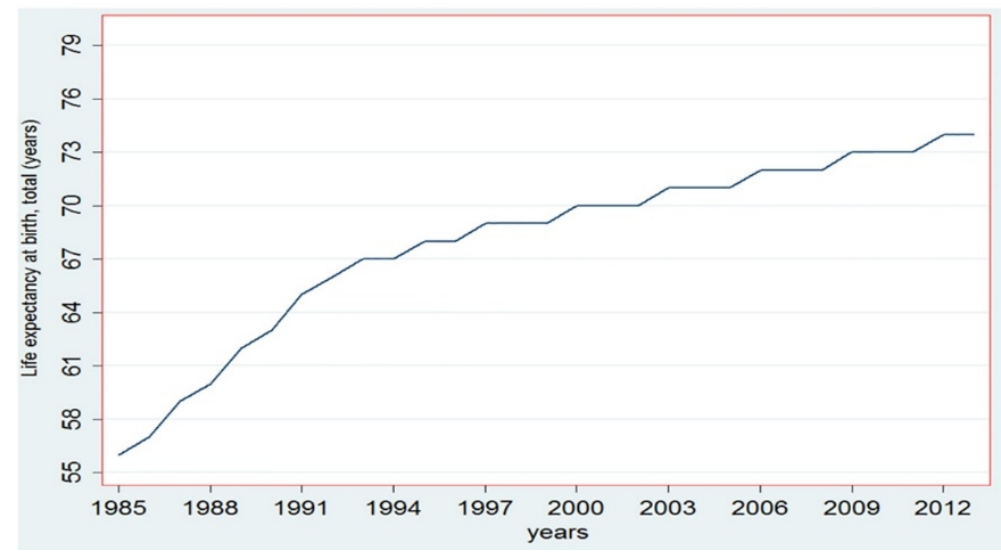

Figure 1. Trend of life expectancy at birth for Iran (1985-2013)

Table 1. Descriptive statistics of the variables used in the study

\begin{tabular}{|l|l|l|l|l|l|l|}
\hline Variables & 1985 & 2013 & Mean & Std. Dev. & Maximum & Minimum \\
\hline LEB (years) & 56 & 74 & 67.9 & 5.08 & 74 & 56 \\
\hline FPI (2004-2006 = 100) & 42 & 133.3 & 79.5 & 23.3 & 113.3 & 42.1 \\
\hline TFR (births per women) & 6.2 & 1.9 & 3.1 & 1.5 & 6.2 & 1.9 \\
\hline INF ( percentage) & 4.4 & 39.3 & 20.3 & 9.6 & 49.7 & 4.4 \\
\hline DOC (per 10,000 population) & 3.6 & 14.3 & 9.2 & 4.1 & 14.5 & 3.4 \\
\hline $\mathrm{CO}_{2}$ emissions (kg per 2005 US\$ of GDP) & 1.6 & 2.5 & 2.26 & 0.3 & 2.8 & 1.6 \\
\hline URB (urban population \% of total) & 56 & 72 & 63 & 6 & 72 & 53 \\
\hline GDP per capita (current US\$) & 3,590 & 4,763 & 2890 & 1655 & 7006 & 1018 \\
\hline Literacy rate (\%) & 59.1 & 87.8 & 78.6 & 9.27 & 87.8 & 59.1 \\
\hline
\end{tabular}

The results of ADF unit root test at levels I(0) and first differenced I(1) are presented in Table 2 . The results indicated that all variables are stationary at the first difference with a constant and without a constant. In other words, finding from ADF test showed that all variables are stationary at the first difference. The results of multicollinearity of the dependent variables are presented in Table 3 . The results showed the mean of VIF was 55, thus indicating there is a high correlation among explanatory variables. LDOC and LTFR were identified as main resources of the collinearity in the model. For reducing collinearity among variables, we replace the first difference of variables (LTFR and LDOC) in the model, and the results showed the mean of VIF after replacing the first difference was 6.8. This is indicated that the collinearity among explanatory variables is less than 10 , and it is acceptable for the analysis. The results of Shapiro-Wilk W test showed that the residual of the observations are normally distributed $(p=0.3)$ (Table 3$)$. Because of the order of integration I(1), the Engle Granger (EG) test showed that the null hypothesis is rejected, and then the series are cointegrated $(p<0.001)$. The results of OLS model indicated that the food production index, number of doctors per 10,000 population, GDP per capita, and literacy rate have a significant positive impact on life expectancy at birth (Table 4). In addition, there is a positive association between degree of urbanization and $\mathrm{CO}_{2}$ emission with life expectancy, but they are not statistically significant. Total fertility rate and inflation rate have a negative impact on life expectancy, and just the effect of total fertility rate is statistically significant. The elasticity of FPI was 0.231 ; this indicates that a $10 \%$ increase in food production increases life expectancy by $2.3 \%$. Also, the results revealed that a $10 \%$ increase in the number of doctors per 10,000 population increases LEB by $1 \%$, a similar increase in the total fertility rate reduces LEB by $4.5 \%$. The results of estimation model showed that adjusted $\mathrm{R}^{2}$ was 0.9 ; this indicates that there is a high correlation between life expectancy at birth and explanatory variables used in the model. On the other hand, more the $90 \%$ of variation LEB can be explained by explanatory variables used in the model. Also, the F- 
statistics confirmed the null hypothesis that at least one independent variable was not zero. The value of DurbinWatson statistic was closer to 2 , and this indicates there is no autocorrelation.

Table 2. ADF unit-root test of levels and first difference of variables used in the study

\begin{tabular}{|l|l|l|l|l|l|}
\hline \multirow{2}{*}{ Variables } & \multicolumn{2}{l|}{ Intercept } & \multicolumn{2}{l|}{ Without Intercept } & \multirow{2}{*}{} \\
\cline { 2 - 6 } & Level & 1st Diff & Level & 1st Diff & Order of integration \\
\hline LLEXP & -2.34 & -5.34 & 1.20 & 4.720 & I(1) \\
\hline LTFR & -1.89 & -3.89 & -2.98 & -8.67 & $\mathrm{I}(1)$ \\
\hline LGNI & -2.80 & -3.80 & -1.29 & -6.40 & $\mathrm{I}(1)$ \\
\hline LINF & -2.84 & -4.59 & -0.39 & -4.65 & $\mathrm{I}(1)$ \\
\hline LFPI & -1.67 & -6.31 & 2.33 & 3.63 & $\mathrm{I}(1)$ \\
\hline LURB & -0.31 & -4.84 & 1.79 & -4.50 & $\mathrm{I}(1)$ \\
\hline LCO & -0.239 & -6.06 & 2.77 & -4.24 & $\mathrm{I}(1)$ \\
LDOC & -1.16 & -3.34 & 2.81 & -3.63 & $\mathrm{I}(1)$ \\
LLIT & -0.86 & -3.78 & 1.9 & 4.21 & $\mathrm{I}(1)$ \\
\hline
\end{tabular}

Table 3. Variance inflation factor (VIF) and tolerance collinearity test

\begin{tabular}{|l|l|l|l|l|l|}
\hline Variables & VIF & Tolerance Index & & VIF & Tolerance Index \\
\hline LDOC & 150 & 0.006 & D.LDOC & 20 & 0.047 \\
\hline LTFR & 136 & 0.007 & D.LTFR & 13 & 0.073 \\
\hline LFPI & 74 & 0.013 & LFPI & 6 & 0.167 \\
\hline LURB & 43 & 0.023 & LURB & 5 & 0.198 \\
LLIT & 23 & 0.076 & LLIT & 4 & 0.22 \\
\hline LGNI & 8 & 0.12 & LGNI & 4 & 0.237 \\
\hline LCO $_{2}$ & 5 & 0.16 & LCO2 & 2 & 0.381 \\
\hline LINF & 1 & 0.54 & LINF & 1 & 0.63 \\
\hline Mean & 55 & - & Mean & 6.8 & \\
\hline
\end{tabular}

Table 4. Results of socioeconomic determinant of life expectancy at birth for Iran (1985-2013)

\begin{tabular}{|l|l|l|l|l|}
\hline Variables & Coefficient & Std. Err. & $\mathrm{t}$ & $p$-value \\
\hline LFPI & 0.231 & 0.033 & 7.01 & $<0.0001$ \\
\hline d.LTFR & -0.452 & 0.179 & -2.52 & 0.023 \\
\hline LINF & -.051 & 0.090 & -0.57 & 0.579 \\
\hline d.LDOC & 0.10 & 0.050 & 2.22 & 0.036 \\
\hline LCO $_{2}$ & 0.063 & 0.045 & 1.39 & 0.185 \\
\hline LURB & 0.037 & 0.154 & 0.24 & 0.811 \\
\hline LGDP & .044 & .012 & 3.58 & 0.003 \\
LLIT & 0.32 & 0.065 & 4.5 & $<0.0001$ \\
\hline Constant & 2.93 & 0.48 & 6.12 & $<0.0001$ \\
\hline
\end{tabular}

Adj $\mathrm{R}^{2}=0.9$, F-Stat. $=98.6, \mathrm{DW}=1.9$

\section{Discussion}

Life expectancy at birth is considered one of the main indicators to examine the situation of health status in developed as well as developing countries. In Iran, the life expectancy increased from 56 years in 1985 to 74 years in 2013. The change in life expectancy is associated with long-term changes in many factors such as food production index, urbanization degree, gross domestic production, total fertility rate, $\mathrm{CO} 2$ emission, number of doctors, inflation rate, and literate rate. Using Iranian's time series data, the present study attempted to investigate the impact on main explanatory variables of life expectancy over the periods of 1985-2013. Our findings indicated that food availability has a significant positive effect on life expectancy, and its coefficient was 0.23 . This implies a $10 \%$ increase in food availability associated with an increase in LEB, on the average, by $2.3 \%$. This finding is in line with studies conducted in less developed countries by Lin et al. (5), Sub-Saharan Africa by Faiyssa et al. (18) and in Eastern Mediterranean Region by Bayatti et al. (6). Ferda investigated the main determinants of life expectancy in Turkey for the period from 1965-2005 by ARDL approach (19). He concluded that food availability is the most important factor for improving longevity, and there is a positive significant association between food availability and life expectancy in Turkey. In 
addition, gross domestic production (GDP) per capita is considered to be another factor that had a positive and statistically significant effect on life expectancy. This finding can be explained by the fact that higher income per capita is associated with consumption of the goods and services with high quality, better housing, and better quality of medical services, which lead to increasing life expectancy $(6,18)$. The direct association between GDP per capita and life expectancy has been shown in previous studies $(6,18,20,21)$. Our empirical analysis indicates that literacy rate also has a positive significant effect on life expectancy. This finding is conforms to results from previous studies $(1,6,18,21)$. In addition, it has been shown that individuals with more education earn higher wages. A greater wage is equal to higher average household income, thus enabling people to increase the quality and quantity of the healthcare services that they purchase. Moreover, people with more education had higher sensitivity and awareness about proper nutrition, hygiene, and healthcare services as well as common illness-preventative measures (6).

Another factor that has an impact on life expectancy is access to health service. We used the number of doctors per 10,000 population as a proxy for access to healthcare. The present study indicates a positive and statistically significant relationship between number of doctors per 10,000 populations and LEB. This can be explained by the fact that increasing the number of physicians may improve accessibility to primary and basic medical services, which increases the utilization of health services and leads to longevity. In others word, shortage of medical personnel, particularly physicians, cause most people to not find a way to obtain ordinary medical care. A study conducted by Balan and Jaba (2) demonstrated that $10 \%$ increase in the number of doctors increases LEB by 0.07 in Romania. Rogers and Wofford (22) have investigated that the main determinants of life expectancy for developing countries. Their study revealed that the doctors per population play an important role in improving life expectancy in a developing nation. We expected the coefficient of $\mathrm{CO} 2$ emissions on LEB was negative, but, similar to other studies $(6,18,23)$, our finding indicated that the $\mathrm{CO} 2$ emission has a positive (albeit statistically insignificant) effect on life expectancy in Iran. Ali and Ahmad (23) have examined the impact of socioeconomic factors on life expectancy in the Sultanate of Oman over the period of 1970 to 2012. The authors found a positive and insignificant direction between CO2 emission and life expectancy, for which its coefficient is 0.21 . They concluded that fossil fuels are the chief energy source of modern civilization. Accordingly, global carbon dioxide $(\mathrm{CO} 2)$ emissions have increased rapidly along with life expectancy and per capita income.

Our results showed that degree of urbanization and higher education level have a positive and insignificant statistically impact on life expectancy in Iran. The positive effect degree of urbanization on LEB can be explained by the fact that people living in urban areas have more access to healthcare services. In addition, people who are living in urban areas have more opportunities to more education, which makes them live longer. This finding is in line with the findings of Bayatti et al. (21) in the Western Pacific Region, Kabir et al. (8) in developing countries, and Fayissa et al. (18) in Sub-Saharan Africa. A study by Bayatti et al. (6) also demonstrated a positive relationship between degree of urbanization and life expectancy in EMR countries. In contrast with our findings, a study conducted by Halicioglu in Turkey showed the degree of urbanization has a negative effect on life expectancy (19). The total fertility rate (TFR) had a negative and statistically significant effect on LEB in Iran. This finding conforms with the studies conducted by Ali and Ahmad (23) in Oman, Singariya (24) in India and Hussain (25) in 91 developing countries. Also, our results indicated that inflation rate has a negative (albeit insignificant statistically) effect on life expectancy in Iran. Shahbaz et al. (4) have examined the determinants of life expectancy in Pakistan between 1972 and 2012. In their study, the misery index (inflation + unemployment) was used as one of the main determinants. The authors concluded that the misery index has a negative and significant impact on life expectancy in Pakistan.

\section{Limitations}

This study has several limitations, and our findings should be interpreted with caution based on these limitations. First, there are other important factors (e.g., employment rate, healthcare spending, exchange rate), which might have played important roles in the life expectancy over the last three decades in Iran. These factors, however, were excluded from the study due to the lack of time series information. Second, in this study only aggregate data were included in the model; although the analysis of the determinants of life expectancy can be improved, only data on type of individual behaviors such as smoking and food habits (consumption of fats, sugar, fruits, and vegetables) are available and included in the model.

\section{Conclusions}

Life expectancy at birth could be affected by several factors, including food availability, literacy rate, numbers of doctors per 10,000 population, GDP per capita, and total fertility rate. Although some other factors such as urbanization and $\mathrm{CO} 2$ emission can have a moderate impact on life expectancy, we could not find evidence to support 
it. The results suggested, however, that, in order to improve life expectancy in the country, health policymakers should focus on the factors that reside outside the healthcare system. Finally, some other factors such as employment rate and healthcare spending are not included in the model, and future research may investigate how these factors have an impact on life expectancy in Iran.

\section{Acknowledgments:}

We thank Dr. Moradi from the Department of Health Management and Economics (School of Public Health, Tehran University of Medical Sciences) for improving our use of the English language in the manuscript. The authors appreciate all people who helped them in this project.

\section{Conflict of Interest:}

There is no conflict of interest to be declared.

\section{Authors' contributions:}

All authors contributed to this project and article equally. All authors read and approved the final manuscript.

\section{References:}

1) Bilas V, Franc S, Bošnjak M. Determinant factors of life expectancy at birth in the European Union countries. Coll Antropol. 2014; 38(1): 1-9. PMID: 24851591.

2) Balan Ch, Jaba E. Statistical analysis of the determinants of life expectancy in Romania. Romanian Journal of Regional Science. 2011; 5(2): 25-38.

3) Sede PI, Ohemeng W. Socio-economic determinants of life expectancy in Nigeria (1980-2011). Health Econ Rev. 2015; 5: 2. doi: 10.1186/s13561-014-0037-z. PMID: 25853000, PMCID: PMC4384885.

4) Shahbaz M, Loganathan N, Mujahid N, Ali A, Nawaz A. Determinants of Life Expectancy and its Prospects Under the Role of Economic Misery: A Case of Pakistan. Social Indicators Research. 2016; 126(3): 12991316.

5) Lin RT, Chen YM, Chien LC, Chan CC. Political and social determinants of life expectancy in less developed countries: a longitudinal study. BMC Public Health. 2012; 12: 85. doi: 10.1186/1471-2458-12-85. PMID: 22280469 , PMCID: PMC3331806.

6) Bayati M, Akbarian R, Kavosi Z. Determinants of life expectancy in eastern Mediterranean region: a health production function. Int J Health Policy Manag. 2013; 1(1): 57-61. doi: 10.15171/ijhpm.2013.09. PMID: 24596837, PMCID: PMC3937941.

7) Shaw JW, Horrace WC, Vogel RJ. The determinants of life expectancy: an analysis of the OECD health data. Southern Economic Journal. 2005; 71(4): 768-83. doi: 10.2307/20062079.

8) Kabir M. Determinants of life expectancy in developing countries. Journal of Developing areas. 2008; 41(2): 185-204. doi: $10.1353 /$ jda.2008.0013.

9) Gulis G. Life expectancy as an indicator of environmental health. Eur J Epidemiol. 2000; 16(2): 161-5. doi: 10.1023/A:1007629306606. PMID: 10845266.

10) The world bank. Life expectancy at birth, total (years). Available from: http://data.worldbank.org/indicator/SP.DYN.LE00.IN?page $=6$

11) Granger C, Newbold P. Spurious regressions in econometrics. Journal of Econometrics. 1974; 2(2): 111-20. doi: 10.1016/0304-4076(74)90034-7.

12) Dickey DA, Fuller WA. Likelihood ratio statistics for autoregressive time series with a unit root. Econometrica. 1981; 49(4): 1057-72. doi: 10.2307/1912517.

13) Engle R, Granger C. Co-Integration and Error-Correction: Representation, Estimation, and Testing. Econometric Society Monographs. 1987; 55(2): 251-76. doi: 10.2307/1913236.

14) Verbeek M. A guide to modern econometrics. editor. John Wiley \& Sons. 2012.

15) Engle RF, Granger CW. Co-integration and error correction: representation, estimation, and testing. Econometrica. journal of the Econometric Society. 1987; 55(2): 251-76. doi: 10.2307/1913236.

16) Greene WH. Econometric analysis: 2nd edition. Pearson Education India. 2003.

17) Gujarati DN. Basic econometrics. 3rd edition. New York. Tata McGraw-Hill Education. 2012.

18) Fayissa B, Gutema P. The Determinants of Health Status in Sub-Saharan Africa (SSA). American Economist 2005; 49(2): 60-6. doi: 10.1177/056943450504900207.

19) Halicioglu F. Modeling life expectancy in Turkey. Economic Modelling. 2011; 28(5): 2075-82. doi: 10.1016/j.econmod.2011.05.002. 
20) Lei H, Li L, Liu X, Mao A. Quantitative study on socioeconomic Determinants of life expectancy in Beijing, China. J Evid Based Med. 2009; 2(2): 92-8. doi: 10.1111/j.1756-5391.2009.01022.x. PMID: 21348995.

21) Bayati M, Akbarian R, Kavosi Z, Sadraei Javaheri A, Amini Rarani M, Delavari S. Socioeconomic Determinants of Health in Western Pacific Region: A Panel Data Analysis. Social welfare quarterly. 2013; 12(47): 111-30.

22) Rogers RG, Wofford S. Life expectancy in less developed countries: socioeconomic development or public health? J Biosoc Sci. 1989; 21(2): 245-52. doi: 10.1017/S0021932000017934. PMID: 2722920.

23) Ali A, Ahmad K. The Impact of Socio-Economic Factors on Life Expectancy in Sultanate of Oman: An Empirical Analysis. Middle-East Journal of Scientific Research. 2014; 22(2): 218-24.

24) Singariya M. Principal Component Analysis of socioeconomic factors and their association with life expectancy in India. Journal of Economics. 2013; 113: 163-72.

25) Husain AR. Life expectancy in developing countries: a cross-section analysis. Bangladesh Development Studies. 2002; 28(1-2): 161-78. 